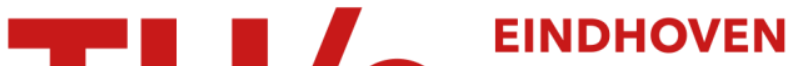 UNIVERSITY OF TECHNOLOGY
}

\section{A building-transmission model for improved propagation prediction in urban microcells}

\section{Citation for published version (APA):}

Jong, de, Y. L. C., Koelen, M. H. J. L., \& Herben, M. H. A. J. (2004). A building-transmission model for improved propagation prediction in urban microcells. IEEE Transactions on Vehicular Technology, 53(2), 490-502. https://doi.org/10.1109/TVT.2004.823491

DOI:

10.1109/TVT.2004.823491

Document status and date:

Published: 01/01/2004

\section{Document Version:}

Publisher's PDF, also known as Version of Record (includes final page, issue and volume numbers)

\section{Please check the document version of this publication:}

- A submitted manuscript is the version of the article upon submission and before peer-review. There can be important differences between the submitted version and the official published version of record. People interested in the research are advised to contact the author for the final version of the publication, or visit the $\mathrm{DOI}$ to the publisher's website.

- The final author version and the galley proof are versions of the publication after peer review.

- The final published version features the final layout of the paper including the volume, issue and page numbers.

Link to publication

\section{General rights}

Copyright and moral rights for the publications made accessible in the public portal are retained by the authors and/or other copyright owners and it is a condition of accessing publications that users recognise and abide by the legal requirements associated with these rights.

- Users may download and print one copy of any publication from the public portal for the purpose of private study or research.

- You may not further distribute the material or use it for any profit-making activity or commercial gain

- You may freely distribute the URL identifying the publication in the public portal.

If the publication is distributed under the terms of Article 25fa of the Dutch Copyright Act, indicated by the "Taverne" license above, please follow below link for the End User Agreement:

www.tue.nl/taverne

Take down policy

If you believe that this document breaches copyright please contact us at:

openaccess@tue.nl

providing details and we will investigate your claim. 


\title{
A Building-Transmission Model for Improved Propagation Prediction in Urban Microcells
}

\author{
Yvo L. C. de Jong, Member, IEEE, Maikel H. J. L. Koelen, and Matti H. A. J. Herben, Senior Member, IEEE
}

\begin{abstract}
This paper presents a model for the propagation of radiowaves through buildings. The model can be used as a seamless extension to ray-based propagation prediction models that only consider external reflection and diffraction, as do most current models. This involves the use of so-called transmitted rays, which are traced through building walls. Outdoor-to-indoor propagation (building penetration) is automatically taken into account as a "by-product." The transmission model requires no information about each building's interior other than a specific attenuation factor that describes the global behavior of the field inside the building. This coefficient can be determined for individual buildings by measuring the excess loss associated with the propagation path through the building. It is shown, however, that no large errors are to be expected if all buildings are characterized by the average of the empirical values obtained in this study, at 1.9 GHz. Path loss predictions generated with the aid of the new model are shown and compared with measured data to illustrate the considerable improvement in accuracy that can be achieved in realistic urban microcell scenarios by taking into account building penetration and transmission.
\end{abstract}

Index Terms-Building penetration and transmission, mobile communication, radio propagation, urban microcells.

\section{INTRODUCTION}

W ITH the advent of microcellular radio networks likely to be employed in third-generation mobile communication systems, there is an increased interest in propagation models that are able to provide location-specific predictions of channel parameters such as local mean power and delay spread. Ray-based propagation prediction, in which the propagation of radiowaves is described in terms of straight trajectories in space called rays, has emerged as the most successful technique for this purpose. Quasi-two-dimensional ray-based models (often simply called two-dimensional or 2-D models) are quite adequate if transmit and receive heights are well below the average rooftop level [1], [2], as is normally the case in urban microcells. These models have been reported to provide excellent prediction results for a

Manuscript received June 11, 2002; revised October 23, 2003 and November 24, 2003. This work was supported by KPN Research (now TNO Telecom), Leidschendam, The Netherlands.

Y. L. C. de Jong was with the Eindhoven University of Technology, 5600 MB Eindhoven, The Netherlands. He is now with the Communications Research Centre Canada (CRC), Ottawa, ON K2H 8S2, Canada (e-mail: yvo.dejong@crc.ca).

M. H. J. L. Koelen was with the Eindhoven University of Technology, 5600 MB Eindhoven, The Netherlands. He is now with Vodafone Netherlands, 6201 BM Maastricht, The Netherlands (e-mail: maikel.koelen@ vodafone.com).

M. H. A. J. Herben is with the Eindhoven University of Technology, 5600

MB Eindhoven, The Netherlands (e-mail: m.h.a.j.herben@tue.nl).

Digital Object Identifier 10.1109/TVT.2004.823491 variety of urban scenarios. In many other cases, however, these models do not provide the same accuracy that can presently be achieved for macrocells.

Although currently available ray-tracing tools vary widely with regard to the implementation of the ray-tracing algorithm itself, they are generally based on models of the same propagation mechanisms: line-of-sight (LoS) propagation, reflection, and diffraction. In a number of frequently occurring scenarios, these mechanisms alone do not adequately explain the channel properties actually observed. In particular, scattering from trees located near street intersections can play an important role with regard to propagation around street corners [3], [4] and, as will be shown in this paper, transmission of radiowaves through buildings is often significant behind buildings obstructing the LoS to the base station antenna [5], [6].

Propagation research for mobile communications in urban microcells has hitherto been focused mainly on the modeling of reflection and diffraction from the exterior walls and corners of buildings. These buildings are usually treated as being opaque at frequencies used for terrestrial mobile communications. There does exist a limited amount of published material on outdoor-to-indoor propagation [7]-[12] and propagation through buildings [13], [14], but at present no building-transmission models are available that can be readily incorporated in ray-based propagation prediction tools.

Rigorous computation of the effects of propagation into, within, and through buildings, using, e.g., the method of moments [15], finite-difference time domain (FDTD) methods [16], [17], or indoor ray-tracing [18], [19] is generally much too complex in the context of cellular network planning. Also, it presumes the availability of detailed knowledge of the buildings' geometrical and dielectric properties, both external and internal. In the practice of cell planning, such information is not available. In fact, in order for a building-transmission model to be of practical value, it should be simple and require only a minimum of information about the buildings.

This paper presents a building-transmission model that requires each building's exterior coordinates and dielectric permittivity, as well as one additional coefficient that characterizes the attenuation in the building interior. This coefficient $\alpha_{b}$ can be determined for individual buildings by measuring the excess loss associated with the propagation path through the building. However, as will be shown later in this paper, no large errors are to be expected if all buildings are characterized by the same average value $\left(\alpha_{b}=2.1 \mathrm{~dB} / \mathrm{m}\right.$ at $\left.1.9 \mathrm{GHz}\right)$. As the new model finds its application in propagation prediction for urban microcell environments, it is kept quasi-two-dimensional. This means that it will be assumed that the reception point and the source 
of the incident field are at the same height and that the buildings are very high. The wave propagation is in three-dimensional (3-D) space, as usual. Although it is straightforward to extend the model to arbitrary polarization, in this paper attention is restricted to the vertically polarized field components, so that all expressions become scalar. The new model can be seamlessly integrated into existing ray-based propagation prediction tools, although it requires the ray-tracing engine to be modified such that it can handle rays going through one or more building walls.

The organization of this paper is as follows. The new building-transmission model is presented in Section II and Section III provides numerical results generated by this model. In Section IV, empirical values of the attenuation coefficient $\alpha_{b}$ are obtained by fitting the model to measurements taken in the deep shadow regions behind various buildings. Section V illustrates the considerable improvement in prediction accuracy that can be achieved in a realistic microcellular scenario by considering building penetration and transmission. Conclusions are drawn in Section VI.

\section{BUILDING-TRANSMISSION MODEL}

An illustration of the building model adopted in the present study is given in Fig. 1. As is usually done in 2-D propagation prediction for microcell environments, each building is modeled as an infinitely high object with planar faces representing the exterior walls (including windows, doors, etc.). The exterior building surface will be denoted by $S$ and the unit vector $\hat{\mathbf{n}}$ is the normal vector of $S$, which points into the free space surrounding the building. Reflection and diffraction are assumed both to be independent of the (unknown) interiors of the buildings and to be determined completely by the complex permittivity $\epsilon_{r}$ of their exterior walls. This assumption, which appears to be quite reasonable and is implicitly made in most ray-based propagation prediction tools, permits the building-transmission model of this paper to be integrated seamlessly into existing tools.

Obviously, as in outdoor environments, radio propagation inside buildings is governed by mechanisms such as reflection, diffraction, and scattering from various objects. The field distribution inside a building is therefore dependent on specific features of its internal structure (e.g., layout, construction materials). As no knowledge is available about these features, it is impossible to predict the exact internal field distribution. Instead, in an attempt to capture the global behavior of the internal and transmitted fields, the building interior is treated as a homogeneous medium in which the excess propagation loss (the path loss relative to the free-space loss) can be described by a specific attenuation factor $\alpha_{b}$, expressed in decibels per meter, and the propagation velocity is equal to that in free space. Hence, the field $E^{\text {in }}(\mathbf{r})$ inside the building is governed by the effective propagation constant

$$
K=k-\frac{j \alpha_{b}}{20 \log _{10} e}=k-\frac{j \alpha_{b}}{8.686}
$$

in which $k$ is the free-space wavenumber and $e$ denotes the natural logarithmic base. In general, rays incident on an interface between free space and a lossy medium are refracted, i.e., the

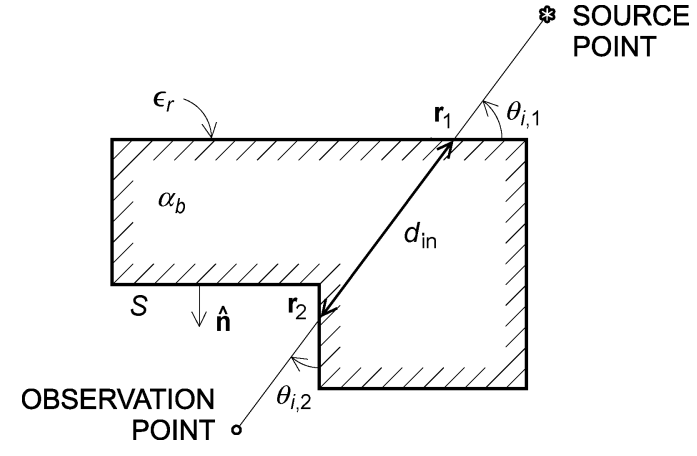

Fig. 1. Illustration of the building model (top view).

transmission angle is not equal to the incidence angle, even if the phase constant in the lossy medium is equal to $k$ [20]. However, as $|\operatorname{Im} K|=\alpha_{b} / 8.686 \ll k$ for the relatively small values of $\alpha_{b}$ found in practice (see Section IV), refraction of rays at the exterior wall can be neglected.

Consider a ray-optical incident field of the general form

$$
E_{i}\left(\mathbf{r}_{0}+s \hat{\mathbf{k}}_{i}\right)=E_{i}\left(\mathbf{r}_{0}\right) \sqrt{\frac{\rho_{1} \rho_{2}}{\left(\rho_{1}+s\right)\left(\rho_{2}+s\right)}} e^{-j k s}
$$

in which $\mathbf{r}_{0}$ is an arbitrary reference point and $E_{i}\left(\mathbf{r}_{0}\right)$ is the incident field at $\mathbf{r}_{0}$. Furthermore, $\hat{\mathbf{k}}_{i}$ is the unit incidence direction vector and $\rho_{1}$ and $\rho_{2}$ are the radii of curvature of the incident wavefront in the vertical and horizontal plane, respectively, evaluated at $\mathbf{r}_{0}$. Let us now choose $\mathbf{r}_{0}$ such that it lies on the surface $S$ of one of the buildings. According to the laws of geometrical optics (GO), the reflected field can be written as

$$
E_{r}\left(\mathbf{r}_{0}+s \hat{\mathbf{k}}_{r}\right)=E_{i}\left(\mathbf{r}_{0}\right) R\left(\mathbf{r}_{0}\right) \sqrt{\frac{\rho_{1} \rho_{2}}{\left(\rho_{1}+s\right)\left(\rho_{2}+s\right)}} e^{-j k s}
$$

in which $\hat{\mathbf{k}}_{r}$ is the unit propagation direction vector of the reflected field, which is related to $\hat{\mathbf{k}}_{i}$ through Snell's law of reflection

$$
\hat{\mathbf{k}}_{r}=\hat{\mathbf{k}}_{i}-2 \hat{\mathbf{n}}\left(\hat{\mathbf{n}} \cdot \hat{\mathbf{k}}_{i}\right) \text {. }
$$

The point $\mathbf{r}_{0}$ is called the reflection point. The reflection coefficient $R\left(\mathbf{r}_{0}\right)$ relates the complex amplitude of the reflected field to that of the incident field and is dependent on the permittivity $\epsilon_{r}$ and the incidence angle $\theta_{i, 0}$, which is defined as the angle that $\hat{\mathbf{k}}_{i}$ makes with respect to $S$, as illustrated in Fig. 1. Here, we use the soft Fresnel reflection coefficient

$$
R\left(\mathbf{r}_{0}\right)=\frac{\sin \theta_{i, 0}-\sqrt{\epsilon_{r}-\cos ^{2} \theta_{i, 0}}}{\sin \theta_{i, 0}+\sqrt{\epsilon_{r}-\cos ^{2} \theta_{i, 0}}}
$$

which pertains to vertical polarization. This reflection coefficient, in combination with values of the complex permittivity $\epsilon_{r}$ within a range that applies to most common building materials, is well known to provide an accurate approximation of the fields reflected from buildings and is used in most ray-based propagation models. A permittivity equal to 5 was shown to be an optimum choice in two independent studies [2], [21] and will be used in the following. Note that for this and larger values of $\epsilon_{r}$, the coefficient (5) is virtually identical to the reflection coefficient for impedance boundaries [22], which 


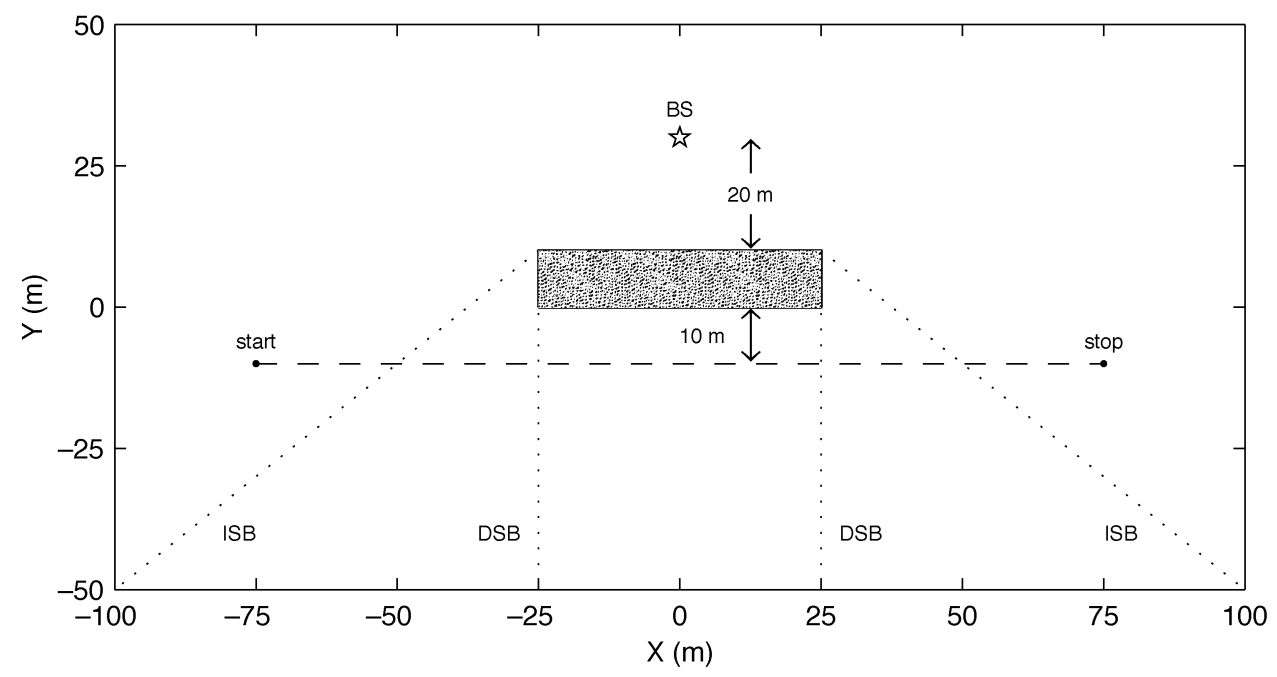

Fig. 2. Configuration of the simulated environment. Observation trajectory and shadow boundaries are indicated by dashed and dotted lines, respectively. "BS" denotes the base station location.

will be used instead of the Fresnel reflection coefficient in Section V.

The GO transmitted field inside the building due to the incident field (2) is given by

$$
E_{t}^{\mathrm{in}}\left(\mathbf{r}_{0}+s \hat{\mathbf{k}}_{t}\right)=E_{i}\left(\mathbf{r}_{0}\right) T\left(\mathbf{r}_{0}\right) \sqrt{\frac{\rho_{1} \rho_{2}}{\left(\rho_{1}+s\right)\left(\rho_{2}+s\right)}} e^{-j K s}
$$

in which $\mathbf{r}_{0}$ is the transmission point, $\hat{\mathbf{k}}_{t}=\hat{\mathbf{k}}_{i}$ is the propagation direction of the transmitted field, and $T\left(\mathbf{r}_{0}\right)$ is the transmission coefficient. Because total power is conserved at the building surface, the part of the incident power that is not reflected back must be transmitted into the building interior, which means that $\left|R\left(\mathbf{r}_{0}\right)\right|^{2}+\left|T\left(\mathbf{r}_{0}\right)\right|^{2}$ must be equal to unity. Neglecting a possible phase jump of the transmitted field at $S$, which is unimportant for the present application in any case, $T\left(\mathbf{r}_{0}\right)$ can therefore be written as

$$
T\left(\mathbf{r}_{0}\right)=\sqrt{1-\left|R\left(\mathbf{r}_{0}\right)\right|^{2}} .
$$

The losses inside the exterior wall are not included in the transmission coefficient. Together with the other losses inside the building, they are accounted for by the attenuation coefficient $\alpha_{b}$.

To compute the field transmitted through the building, consider a ray-optical field of the form

$$
E_{i}^{\mathrm{in}}\left(\mathbf{r}_{0}+s \hat{\mathbf{k}}_{i}\right)=E_{i}^{\mathrm{in}}\left(\mathbf{r}_{0}\right) \sqrt{\frac{\rho_{1} \rho_{2}}{\left(\rho_{1}+s\right)\left(\rho_{2}+s\right)}} e^{-j K s}
$$

that is incident on the surface $S$ from within the building. As before, the reference point $\mathbf{r}_{0}$ is chosen to lie on $S$. Part of the incident field will be reflected back into the building interior, where it is attenuated even further and becomes much weaker than the incident field (8), so that it can safely be neglected. The GO transmitted field outside the building is given by

$$
E_{t}\left(\mathbf{r}_{0}+s \hat{\mathbf{k}}_{t}\right)=E_{i}^{\mathrm{in}}\left(\mathbf{r}_{0}\right) T\left(\mathbf{r}_{0}\right) \sqrt{\frac{\rho_{1} \rho_{2}}{\left(\rho_{1}+s\right)\left(\rho_{2}+s\right)}} e^{-j k s}
$$

where $T\left(\mathbf{r}_{0}\right)$ is the same transmission coefficient as in (7).
The transmission points mentioned above are found with the aid of the generalized Fermat's principle, which states that the optical path length of each transmitted ray must be an extremum - a minimum in the present case-with respect to movement of the transmission point over $S$. In practice, this means that transmitted rays can be traced straight through building walls, as if none were present. The excess attenuation due to the building, which we will call the building-transmission loss, is then found from (6) and (9) to be

$$
L_{t}=\alpha_{b} \cdot d_{\text {in }}-20 \log _{10} T\left(\mathbf{r}_{1}\right)-20 \log _{10} T\left(\mathbf{r}_{2}\right) \quad \mathrm{dB}
$$

where $d_{\text {in }}$ is the length of the transmitted ray path inside the building and $\mathbf{r}_{1}$ and $\mathbf{r}_{2}$ are the transmission points on the surface of the building (see Fig. 1).

The building-transmission model formulated in this section is limited to GO transmitted ray contributions, i.e., internal diffraction, which involves rays penetrating the surface of a building at its vertical edges [23], is not included. The model does not satisfy Maxwell's equations in any formal sense, but, as will become clear in Sections IV and V, with a suitable choice of $\alpha_{b}$, it compares remarkably well with measurements.

\section{NUMERICAL RESULTS}

The model of the previous section is applied here to a simple building configuration. The objective is to investigate the behavior of the total field (consisting of direct, diffracted, and transmitted components) in different regions behind the building. The results of this section are relevant to the experiments discussed in Section IV.

Consider the configuration of Fig. 2, where a transmitter (base station) is located at a fixed position on one side of a building and the receiver is moved along a trajectory on the other side. The frequency is set to $1.9 \mathrm{GHz}$, the permittivity $\epsilon_{r}$ is 5 (the conductivity is zero), and the specific attenuation coefficient $\alpha_{b}$ is chosen to be $2.1 \mathrm{~dB} / \mathrm{m}$, which, as will be shown in Section IV-F, is a realistic value. The diffraction field is computed using Tiberio-Maliuzhinets' diffraction coefficient for an impedance wedge [22]. The field along the trajectory is 


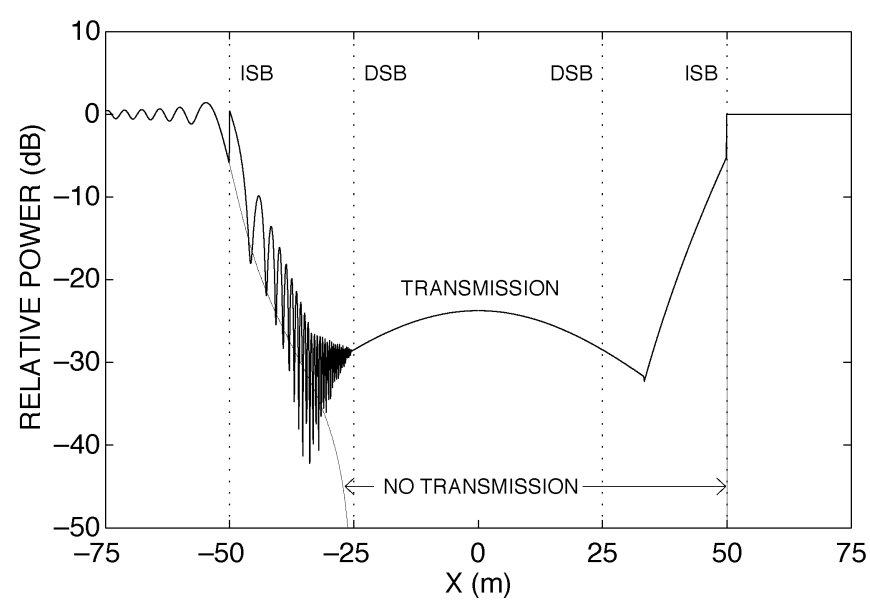

Fig. 3. Received power, relative to the free-space level, for the simulated environment $\left(\epsilon_{r}=5, \alpha_{b}=2.1 \mathrm{~dB} / \mathrm{m}\right)$. The left half of the plot shows the total field and the right half shows GO contribution only. Shadow boundaries are indicated by dotted lines.

shown in Fig. 3, in which the left half of the plot represents the total field (including diffraction) and the right half shows only the GO field. Results for the case of no transmission are shown for comparison. The shadow boundaries of the incident field (ISB) and the diffraction field (DSB) are indicated in both figures.

From Fig. 3, it is clear that building transmission plays a significant role in the shadow region between the ISBs. The transmitted field is comparable in strength with the DSB in the two regions between an ISB and a DSB, just around the building corners, but this is not generally the case. Indeed, as will be illustrated in Section V, in most practical scenarios, transmission through buildings is negligible in areas around the corner from the source. It is further seen in the figure that the total field, including the transmitted component, exhibits discontinuities at the ISBs. These are due to the fact that internal diffraction, which involves transmitted fields that compensate for the discontinuities of the GO transmitted field [23], is not included in the model of Section II. Whether the inclusion of internal diffraction is worth the additional computational complexity is a topic for further study. In Fig. 3, as in general, the most notable effect of building transmission occurs in the deep shadow region behind the building, where the transmitted field is the only contribution. This region, between the DSBs, is where the transmission-loss measurements of the next section were performed.

\section{EXPERIMENTAL RESULTS}

The parameter $\alpha_{b}$ used in the model of Section II is related to the internal building structure in a highly complicated way and must be determined empirically, i.e., from measurements of the building-transmission loss $L_{t}$. A major concern in the measurement of $L_{t}$ is formed by the disturbing effect of multipath contributions entering the receive antenna via objects in the environment of the building considered. A solution to this problem may be found in the use of wide-band and/or directional measurement techniques, which offer the possibility

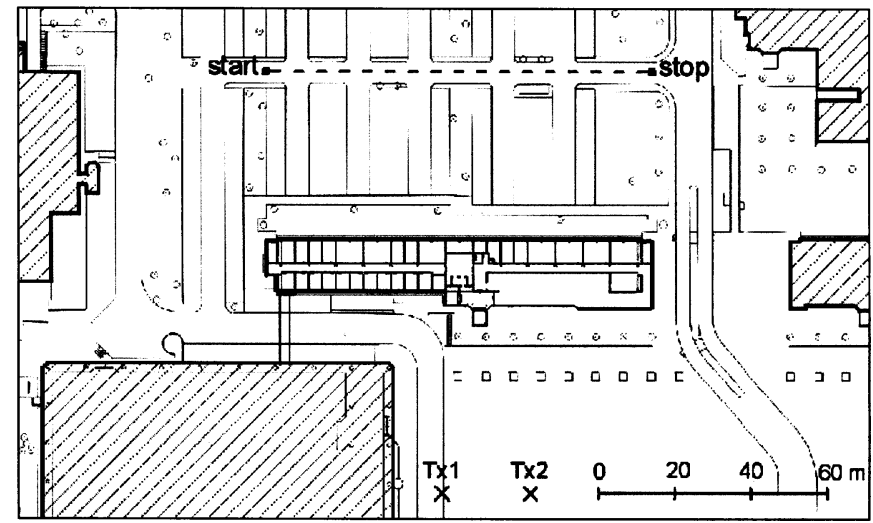

Fig. 4. Plan view of the measurement environment.

to separate multiple waves on the basis of their different propagation delays and angles-of-arrival, respectively [24]. Using a combination of these techniques, it was demonstrated in [5] that it is indeed possible to distinguish the radiowaves transmitted through an obstructing building from other multipath contributions in a realistic microcell environment. However, important practical disadvantages of this method are the relatively complex measurement procedure and the long time needed to measure the transmitted field, even for a single receiver location.

This section describes a fast, simple, and yet accurate method [6] to measure the transmitted field along a trajectory behind an obstructing building by using a wide-band radio channel sounder. Furthermore, it presents results of building-transmission loss measurements for a set of 22 buildings that are typical for urban environments. Empirical values of the specific attenuation coefficient $\alpha_{b}$ are determined for each of these buildings.

\section{A. Measurement Equipment and Procedure}

The building-transmission measurements discussed in this section were performed using a radio channel sounding system that was described previously in [24]. This system operates at $1.9 \mathrm{GHz}$ and has a temporal resolution of $20 \mathrm{~ns}$. The receive antenna, which was vertically polarized and omnidirectional, was fixed on the roof of a vehicle at $2.4 \mathrm{~m}$ above ground level.

The transmit antenna-a vertically polarized, $12-\mathrm{dBi}$, omnidirectional antenna with a vertical 3 -dB beamwidth of $6^{\circ}$-was positioned on one of the long sides of the building under consideration, at a height of $6.5 \mathrm{~m}$, typical for the base station configuration in urban microcells. During a measurement, impulse response data were recorded every $0.1 \mathrm{~s}$ while the vehicle was moving at a low constant speed (usually around $1.5 \mathrm{~m} / \mathrm{s}$ ) along a straight trajectory on the other side of the building. Road layout and other local circumstances influenced the final choices of the transmit antenna location and the measurement trajectory.

\section{B. Determination of the Transmitted Field}

To illustrate how the absolute transmitted field strength can be determined from the impulse response data, a typical data set - measured behind a 15-m-high office building [see the plan 


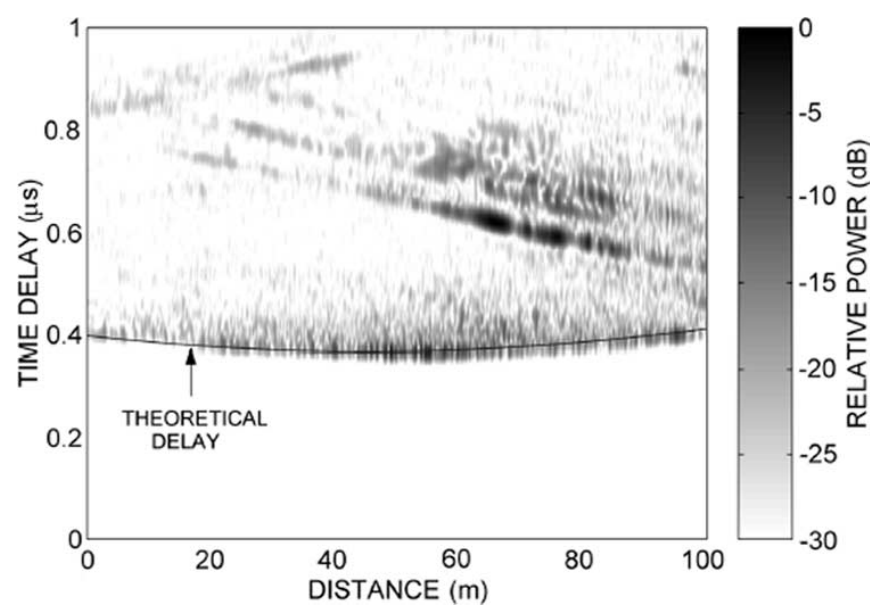

Fig. 5. Measured power delay profiles along the trajectory. Transmitter is at location "Tx1."

in Fig. 4 and the photograph in Fig. 8(f)]—is shown in Fig. 5. In this measurement, the transmit antenna was at the location marked "Tx1" in Fig. 4. The major part of the building consists of small offices separated by brick walls, with wooden doors opening to a central corridor. A large cafeteria is situated in the right part. The building has an external construction of concrete, metal, and glass.

The set of power-delay profiles recorded along the trajectory is denoted by $p(\tau ; d), \tau$ being the propagation delay time and $d$ being the distance along the trajectory. For each $d$, the values of $\tau$ for which $p(\tau ; d)$ has local maxima form estimates of the propagation delays of the dominant multipaths. The value of $p(\tau ; d)$ at each of these $\tau \mathrm{s}$ is proportional to the multipath intensity. The proportionality factor between the two can be determined prior to the measurement by connecting a known attenuation between the transmitter and receiver.

The received field is composed of multiple waves propagating around the building via reflection, diffraction, and scattering from surrounding objects and a contribution due to transmission through the building. The waves propagating around the building arrive at the receive antenna roughly from the front and back of the vehicle. As the distance along the trajectory increases, the profile maxima corresponding to these waves move along the delay axis at an approximately constant rate (see Fig. 5). The sign of this rate depends on whether a wave propagates around the left or right side of the building. Generally, as in Fig. 5, the first transmitted contribution can easily be identified by its hyperbolic shape and because it has minimum delay for all $d$. The weaker "clutter" arriving directly after this first contribution is possibly the result of waves undergoing (multiple) backward and forward reflection in the building interior and will be ignored.

The transmitted field is assumed to be the result of a single transmitted ray propagating directly from the transmit antenna through the building to the receive antenna, at a propagation velocity equal to that in free space (cf. Section II). In Fig. 5, the solid line represents the theoretical delay $\tau_{t}(d)$ associated with the transmitted ray. This delay is seen to be in very good agreement with the measured delay of the first transmitted

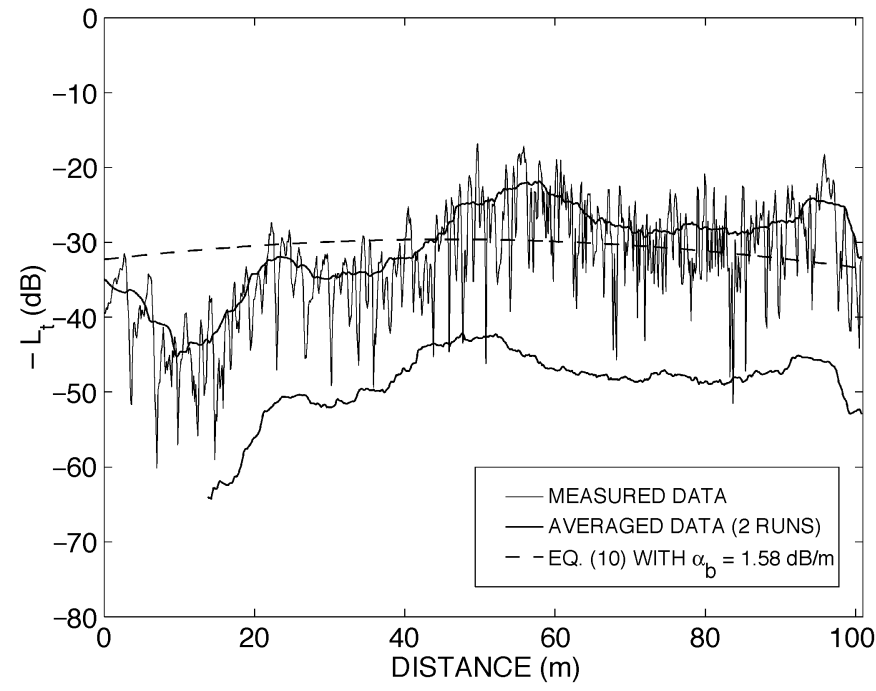

Fig. 6. Measured and modeled building-transmission loss $L_{t}$ (transmit antenna at location "Tx1"). The lower curve has an offset of $-20 \mathrm{~dB}$ for clarity.

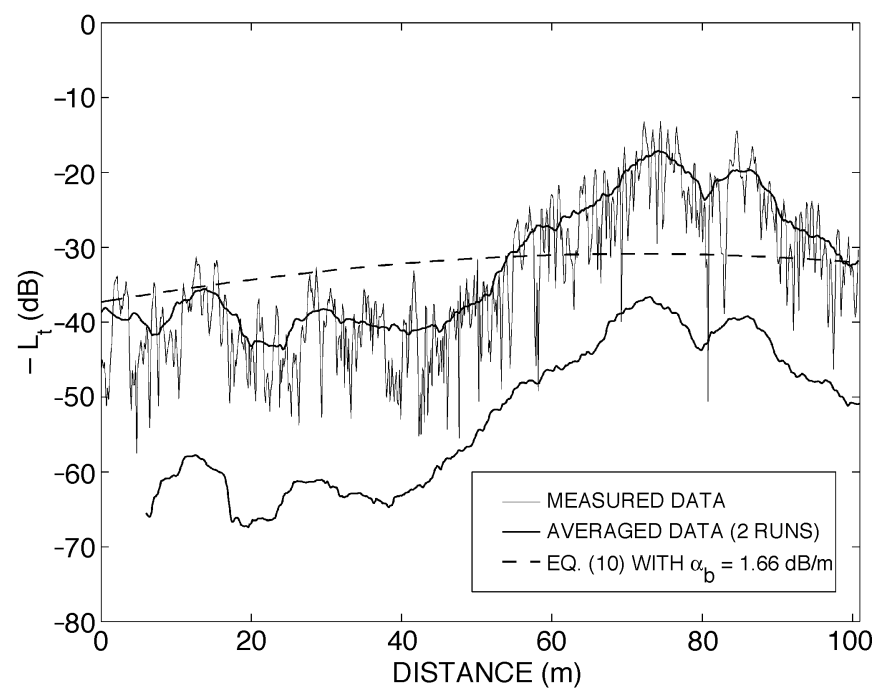

Fig. 7. Measured and modeled building-transmission loss $L_{t}$ (transmit antenna at location "Tx2"). The lower curve has an offset of $-20 \mathrm{~dB}$ for clarity.

TABLE I

BUILDING CATEGORIES

\begin{tabular}{c|l}
\hline Category & Description \\
\hline 1 & Residential houses \\
2 & Multi-storey residential buildings (flats) \\
3 & Mixed commercial/residential buildings \\
4 & Office buildings \\
\hline
\end{tabular}

contribution. The absolute transmitted field strength, required to determine $L_{t}$, is obtained from $p(\tau ; d)$ by setting $\tau=\tau_{t}(d)$ and multiplying by the proportionality factor found in the calibration.

\section{Determination of the Attenuation Coefficient}

The thin solid line in Fig. 6 represents the measured buildingtransmission loss for the example discussed in the previous section. This loss exhibits strong and rapid spatial fluctuations, 
TABLE II

EXTERIOR PROPERTIES OF BUILDINGS SELECTED FOR EXPERIMENTS

\begin{tabular}{|c|c|c|c|c|c|}
\hline \multirow{2}{*}{ Building } & \multirow{2}{*}{ Cat. } & \multirow{2}{*}{ External-side building materials } & \multicolumn{3}{|c|}{ External dimensions ${ }^{\dagger}$} \\
\hline & & & $\mathrm{L}(\mathrm{m})$ & $\mathrm{W}(\mathrm{m})$ & $\mathrm{H}(\mathrm{m})$ \\
\hline 1 & 1 & brick / window glass / ceramic roof tiles & 47 & 10 & 8 \\
\hline 2 & 1 & painted wood / window glass / concrete roof tiles & 46 & 10 & 9 \\
\hline $3^{*}$ & 1 & brick / window glass / concrete roof tiles & 73 & 9 & 9 \\
\hline 4 & 1 & brick / window glass / ceramic roof tiles & 36 & 8 & 8 \\
\hline 5 & 1 & brick / window glass / ceramic roof tiles & 73 & 7 & 9 \\
\hline 6 & 2 & brick / window glass & 57 & 11 & 23 \\
\hline 7 & 2 & brick / wooden panels / window glass & 74 & 11 & 12 \\
\hline 8 & 2 & brick / window glass & 119 & 20 & 14 \\
\hline $9^{*}$ & 2 & reinforced concrete covered with insulating material / glass windows / metal railings & 98 & 12 & 26 \\
\hline 10 & 2 & brick / window glass / metal railings & 67 & 19 & 22 \\
\hline 11 & 3 & brick / window glass & 65 & 9 & 9 \\
\hline 12 & 3 & brick / cement panels / window glass & 36 & 12 & 9 \\
\hline 13 & 3 & brick / cement panels / window glass & 49 & 12 & 9 \\
\hline $14^{*}$ & 3 & brick / cement panels / window glass & 36 & 12 & 9 \\
\hline $15^{*}$ & 3 & brick (ground floor) / concrete panels (upper storeys) / window glass & 58 & 15 & 10 \\
\hline 16 & 4 & brick / window glass & 23 & 13 & 10 \\
\hline 17 & 4 & concrete panels / window glass & 51 & 13 & 12 \\
\hline 18 & 4 & concrete block / dark-tinted window glass & 62 & 13 & 14 \\
\hline $19^{*}$ & 4 & reinforced concrete shell / reflective window glass & 40 & 14 & 23 \\
\hline 20 & 4 & reinforced concrete shell / reflective window glass & 45 & 13 & 26 \\
\hline 21 & 4 & concrete panels / window glass & 39 & 14 & 18 \\
\hline $22^{*}$ & 4 & reinforced concrete covered with metal panels / window glass / metal railings & 102 & 18 & 15 \\
\hline
\end{tabular}

$+\mathrm{L}$ (ength) $\times \mathrm{W}($ idth $) \times \mathrm{H}($ eight $)$.

* Photographs of these buildings are shown in Fig. 8.

which indicates that, in reality, the transmitted field behind the building is the result of two or more waves propagating along paths of approximately the same length. These fast fading effects are neglected for the purpose of fitting the proposed model to the global behavior of the measured transmitted field. The large-scale fading component of the measured $L_{t}$, represented in Fig. 6 by the thick solid line, is obtained by averaging over 40 wavelengths [25], which corresponds to approximately $6 \mathrm{~m}$.

To simplify the determination of $\alpha_{b}$, the building is modeled as a rectangular box having the same length as the actual building and a width equal to its maximum width. The buildingtransmission loss experienced by the transmitted field is modeled by (10). In the case considered here, the incidence angles $\theta_{i, 1}$ and $\theta_{i, 2}$ are equal, so that $T\left(\mathbf{r}_{1}\right)=T\left(\mathbf{r}_{2}\right)$. The specific attenuation factor $\alpha_{b}$ is chosen such that the root-mean-square (rms) error of the theoretical $L_{t}$ with respect to the averaged measured data is minimized. For the example under consideration, this results in a value of $\alpha_{b}=1.58 \mathrm{~dB} / \mathrm{m}$ (for $\epsilon_{r}=5$ ) and the rms error is $5.76 \mathrm{~dB}$. The dashed line in Fig. 6 represents the theoretical $L_{t}$ computed using these parameters. In this particular example, it would be possible to reduce the rms error by using different values of $\alpha_{b}$ for the left and right halves of the building, thus reflecting the fact that there are more internal walls in the left section, as can be seen in Fig. 4.

\section{Reproducibility}

In order to assess the reliability of the transmission-loss measurements and the determination of $\alpha_{b}$, the reproducibility of the experimental results was investigated for the building under present consideration. Important factors that could cause two subsequent measurements to yield different results are 1) physical nonstationarity of the environment; for example, due to movement inside the building, and 2) difficulty to conduct the measurements at exactly the same observation points [2]. The lower curve in Fig. 6 represents the result of a second measurement along the same trajectory, with the transmit antenna at location "Tx 1." Apart from a small misalignment in distance, caused by speed variations of the measurement vehicle, this result is almost identical to that of the first measurement. Fig. 7 shows the results of two consecutive measurements along the same trajectory, but with the transmit antenna at the location indicated as "Tx2" in Fig. 4. Again, the measured $L_{t}$ curve is seen to be well reproducible. Although there is a significant difference with respect to the result for antenna position "Tx1," the value of $\alpha_{b}$ obtained for position "Tर2" is close to the first value, viz. $1.66 \mathrm{~dB} / \mathrm{m}$. This indicates that the measured $\alpha_{b}$ is not very sensitive to the exact measurement configuration and that it is indeed inherent to the internal properties of the building.

\section{E. Description of the Buildings}

The buildings selected for the measurements can be roughly classified into the four categories listed in Table I. Although it might be argued that residential houses (category 1) are more typical of suburban than urban environments, this type of building is sometimes also found in city centers and was, therefore, not left out of consideration. A list of all buildings 


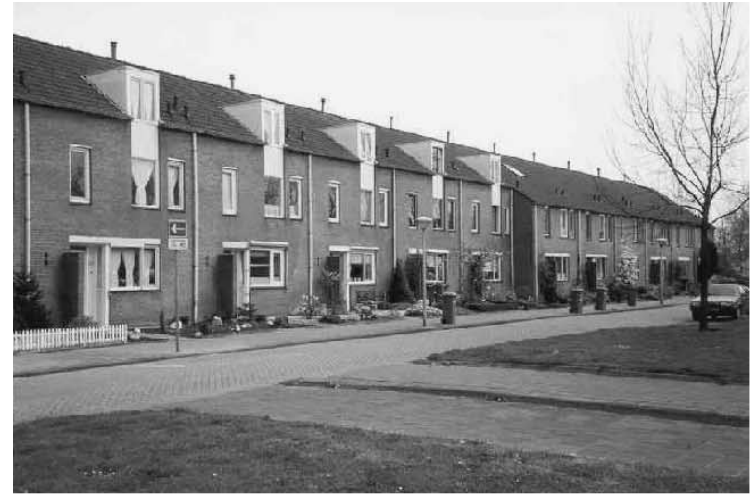

(a)

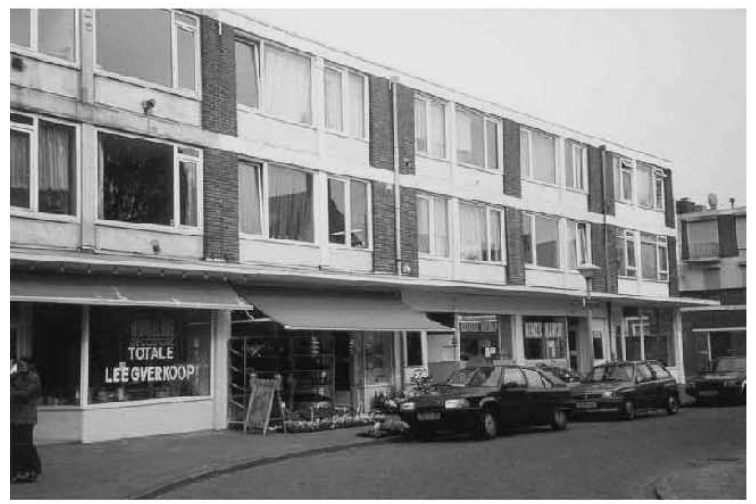

(c)

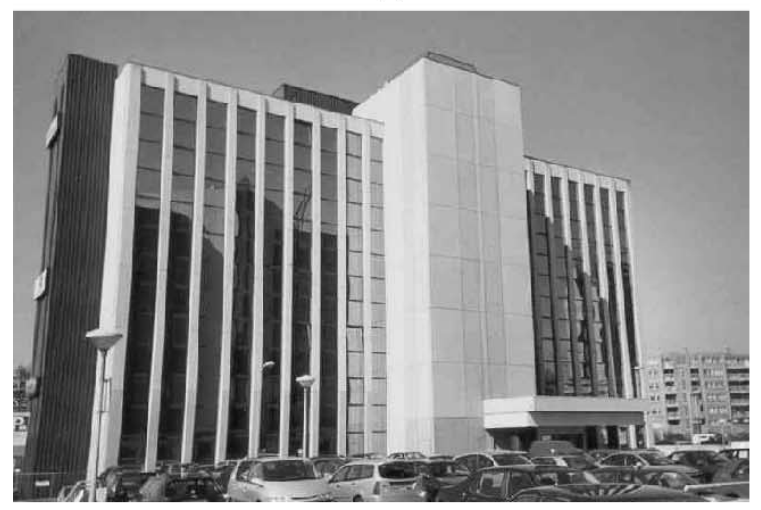

(e)

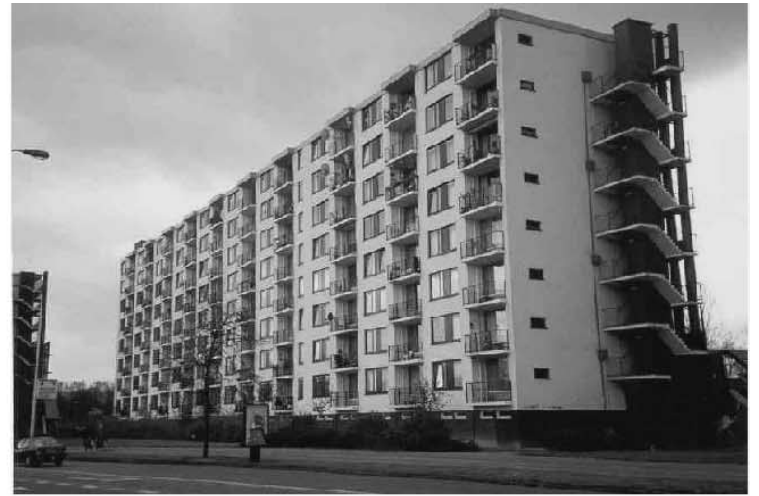

(b)

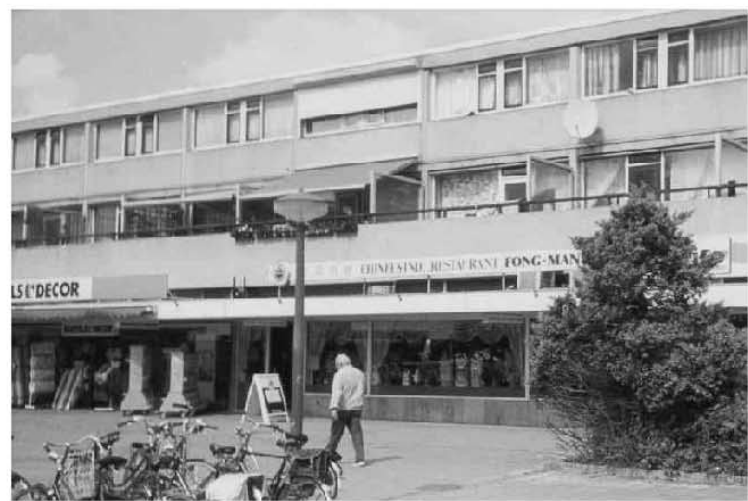

(d)

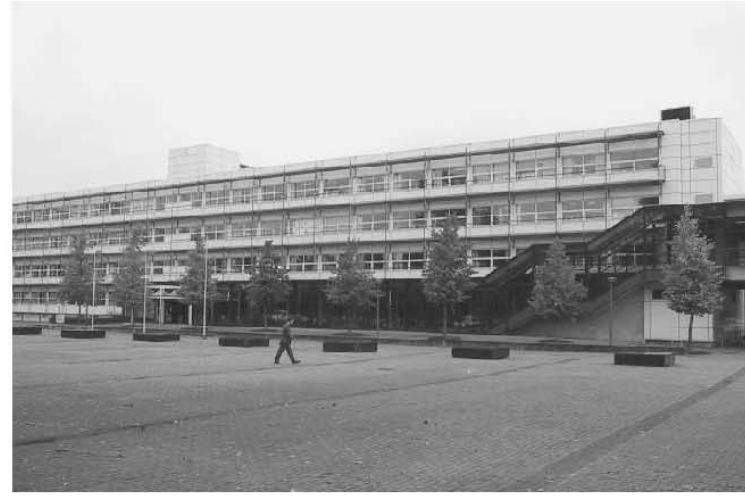

(f)

Fig. 8. Photographs of six of the buildings selected for the experiments. (a) Building 3. (b) Building 9. (c) Building 14. (d) Building 15. (e) Building 19. (f) Building 22.

and their external properties is given in Table II. For buildings consisting of different sections with different heights, the minimum height is specified. For the six buildings in Table II that are marked with an asterisk, plots of the measured building-transmission loss $L_{t}$ are presented and discussed in the next section. Photographs of these buildings are shown in Fig. 8 . The office building discussed previously is referred to as building 22 in Table II and is shown in Fig. 8(f).

\section{F. Results}

By means of the procedure described in Sections IV-B and IV-C, the building-transmission loss $L_{t}$ and the corresponding best fit of $\alpha_{b}$ were determined for the 22 buildings listed in
Table II. Fig. 9(a)-(f) shows the measured $L_{t}$ curves for six of these buildings. For each, the empirical value of $\alpha_{b}$ and the corresponding rms modeling error are given in Tables III-VI, as well as the range in which the averaged measured buildingtransmission loss lies. Overall, $L_{t}$ ranges roughly from 20 to $40 \mathrm{~dB}$.

In general, (10) can be seen to provide a good fit to the measured data when the attenuation factor $\alpha_{b}$ is optimized for the building under consideration, with rms errors around $3 \mathrm{~dB}$. Building 22, which was taken as an illustrative example earlier in this paper, represents a "worst case" in the sense that the rms error achieved for this building is the highest of all. This relatively large error can be explained by the building's internal inhomogeneity, as discussed earlier. 


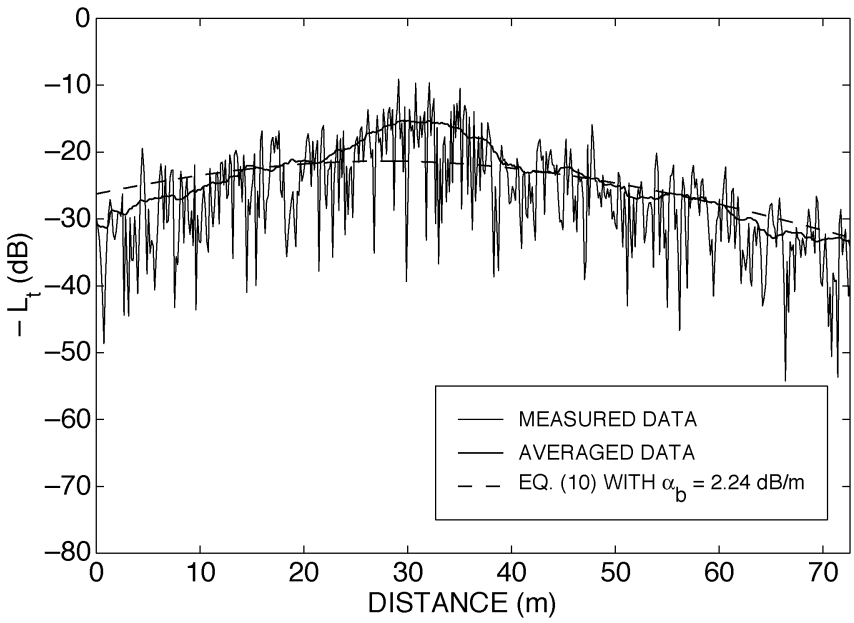

(a)

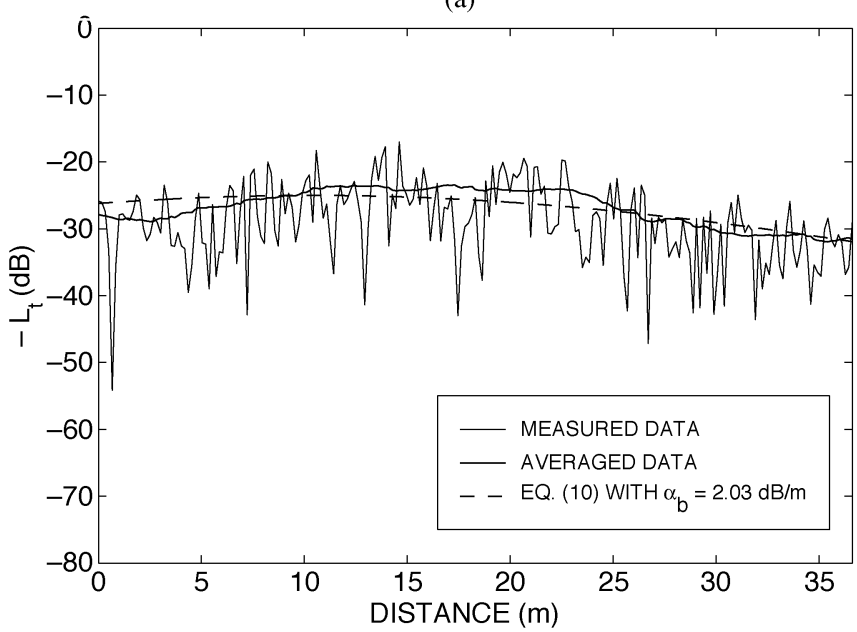

(c)

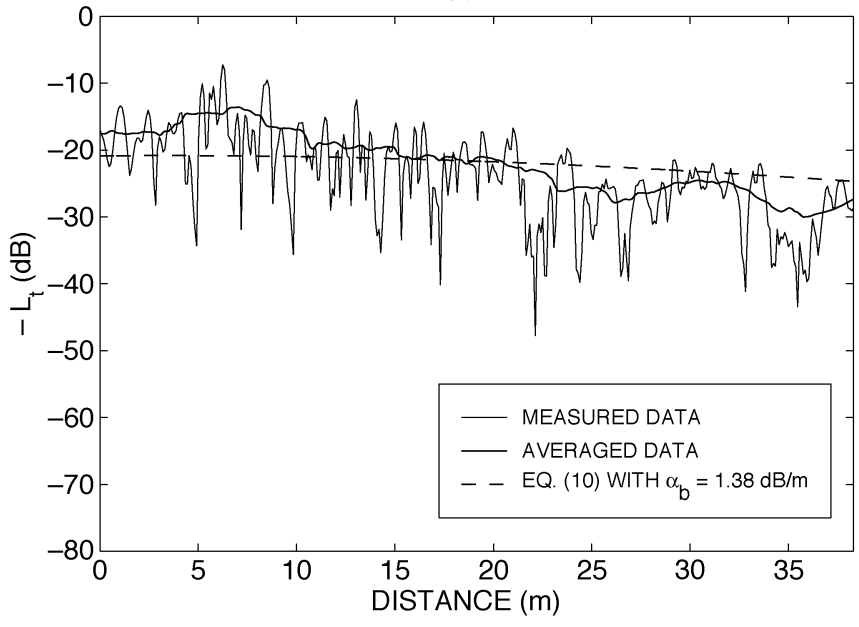

(e)

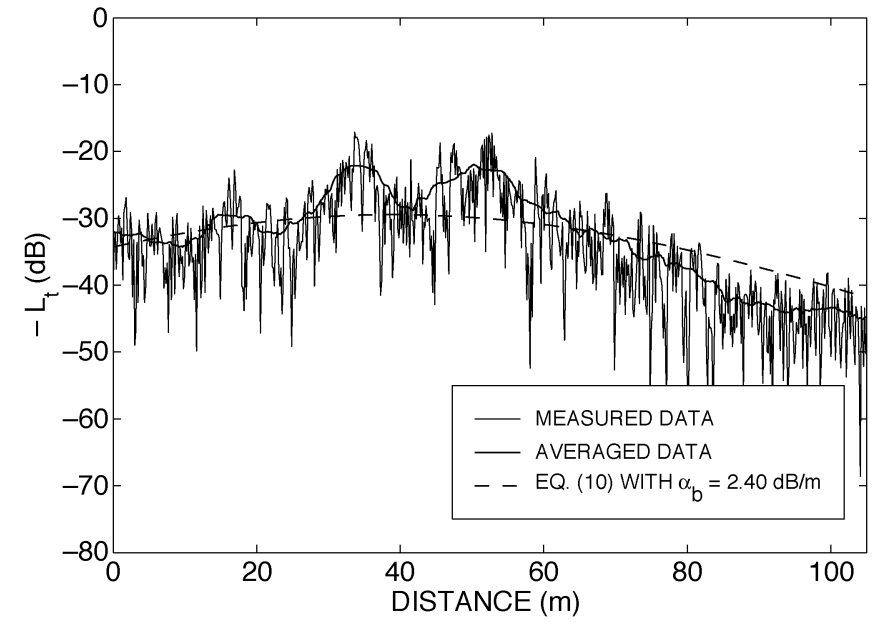

(b)

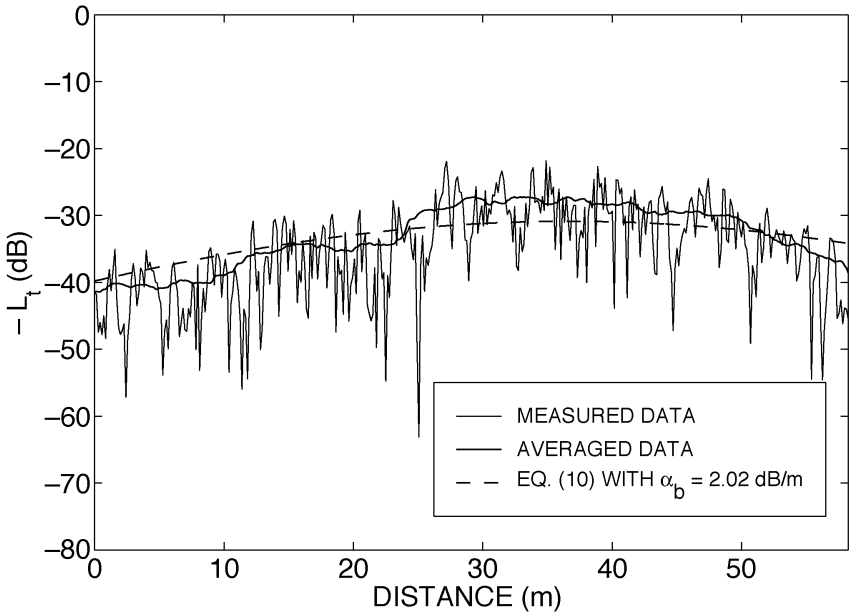

(d)

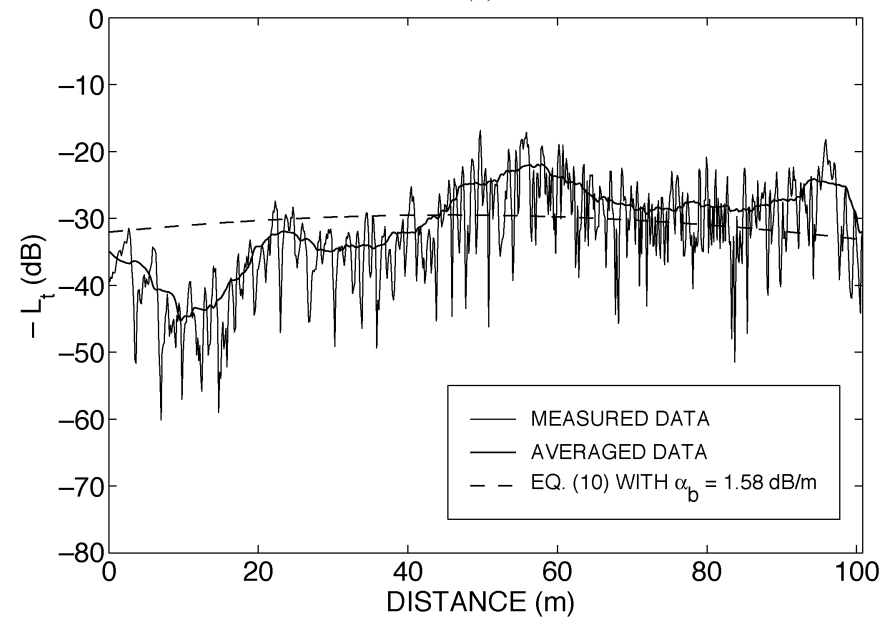

(f)

Fig. 9. Measured and modeled building-transmission loss $L_{t}$ for six of the buildings selected for the experiments. (a) Building 3. (b) Building 9. (c) Building 14 . (d) Building 15. (e) Building 19. (f) Building 22.

The 22 buildings tested can be characterized rather well by the average $\alpha_{b}$ values of their respective categories, which are in turn all close to the total average value of $\alpha_{b}=2.1 \mathrm{~dB} / \mathrm{m}$. This is an indication that the building-transmission model, in combination with an $\alpha_{b}$-value of $2.1 \mathrm{~dB} / \mathrm{m}$, has considerable predictive value. The largest spread around the average value is observed in category 4 (office buildings). This is possibly the result of the widely different internal layouts and the diversity of building materials used in this category. The layouts and materials of the buildings in the other categories are much more uniform. 
TABLE III

MEASURED TRANSMISSION CHARACTERISTICS FOR BUILDINGS OF CATEGORY 1

\begin{tabular}{c|c|c|c}
\hline Building & $\begin{array}{c}\text { Empirical } \\
\alpha_{b}(\mathrm{~dB} / \mathrm{m})\end{array}$ & $\begin{array}{c}\text { Rms error } \\
(\mathrm{dB})\end{array}$ & $\begin{array}{c}\text { Range of } L_{t} \\
(\mathrm{~dB})\end{array}$ \\
\hline 1 & 1.97 & 2.10 & $16-27$ \\
2 & 2.10 & 3.08 & $17-30$ \\
3 & 2.24 & 2.63 & $15-34$ \\
4 & 2.69 & 1.40 & $21-28$ \\
5 & 3.16 & 4.23 & $14-38$ \\
\hline Average & 2.43 & 2.69 & - \\
\hline
\end{tabular}

TABLE IV

MEASURED TRANSMISSION CHARACTERISTICS FOR BUILDINGS OF CATEGORY 2

\begin{tabular}{c|c|c|c}
\hline Building & $\begin{array}{c}\text { Empirical } \\
\alpha_{b}(\mathrm{~dB} / \mathrm{m})\end{array}$ & $\begin{array}{c}\text { Rms error } \\
(\mathrm{dB})\end{array}$ & $\begin{array}{c}\text { Range of } L_{t} \\
(\mathrm{~dB})\end{array}$ \\
\hline 6 & 1.86 & 3.68 & $15-30$ \\
7 & 1.86 & 4.81 & $14-34$ \\
8 & 1.57 & 3.51 & $30-49$ \\
9 & 2.40 & 3.83 & $22-45$ \\
10 & 1.72 & 3.05 & $28-47$ \\
\hline Average & 1.88 & 3.78 & - \\
\hline
\end{tabular}

\section{PREDiction RESUlts}

The objective of this section is to illustrate the improvement in prediction accuracy that can be achieved by incorporating the new building-transmission model in a ray-based propagation model. A comparison is made with measured data.

The predictions in this section were generated for an urban environment in Bern, Switzerland, at $1.89 \mathrm{GHz}$. In the past, extensive microcellular-type measurements were conducted in this area and at this frequency [2], [26]. One of the results of these measurements was that the received field strength behind some of the buildings obstructing the LoS to the base station antenna was significantly higher than predicted if only reflection and diffraction were considered. Additional measurements, based on a high-resolution angle-of-arrival estimation method described in [24], showed that this discrepancy was caused by the fact that some buildings were "leaking" a significant fraction of the field incidence on them. Hence, it was concluded that buildings cannot be considered opaque at frequencies used for terrestrial mobile communications.

The propagation model that produced the predictions is a 2-D ray-tracing model with the following characteristics. Reflected and diffracted fields are computed using the reflection coefficient for impedance boundaries and the corresponding diffraction coefficient of Tiberio-Maliuzhinets [22], respectively. In addition, the model considers transmitted and tree-scattered rays [3], [4]. Each ray can undergo any possible combination of reflection, transmission, diffraction, and scattering, up to a predetermined order. Here, transmission order means the number of walls penetrated. The ray-tracing engine makes use of the concept of virtual sources [2] that, together with the real source (the base station antenna), completely describe the field distribution due to the interaction with the environment. The prediction area is divided into square pixels. For each pixel, the local mean power, required to compute the (local mean) path loss, is obtained using the spatial averaging (SA) method proposed in [27].
TABLE V

MEASURED TRANSMISSION CHARACTERISTICS FOR BUILDINGS OF CATEGORY 3

\begin{tabular}{c|c|c|c}
\hline Building & $\begin{array}{c}\text { Empirical } \\
\alpha_{b}(\mathrm{~dB} / \mathrm{m})\end{array}$ & $\begin{array}{c}\text { Rms error } \\
(\mathrm{dB})\end{array}$ & $\begin{array}{c}\text { Range of } L_{t} \\
(\mathrm{~dB})\end{array}$ \\
\hline 11 & 2.06 & 2.75 & $16-29$ \\
12 & 2.06 & 2.32 & $21-34$ \\
13 & 1.77 & 1.34 & $20-25$ \\
14 & 2.03 & 1.54 & $23-32$ \\
15 & 2.02 & 2.36 & $27-41$ \\
\hline Average & 1.99 & 2.06 & - \\
\hline
\end{tabular}

TABLE VI

MEASURED TRANSMISSION CHARACTERISTICS FOR BUILDINGS OF CATEGORY 4

\begin{tabular}{c|c|c|c}
\hline Building & $\begin{array}{c}\text { Empirical } \\
\alpha_{b}(\mathrm{~dB} / \mathrm{m})\end{array}$ & $\begin{array}{c}\text { Rms error } \\
(\mathrm{dB})\end{array}$ & $\begin{array}{c}\text { Range of } L_{t} \\
(\mathrm{~dB})\end{array}$ \\
\hline 16 & 2.02 & 1.64 & $26-33$ \\
17 & 2.37 & 1.62 & $31-41$ \\
18 & 3.80 & 1.52 & $51-64$ \\
19 & 1.38 & 3.59 & $14-30$ \\
20 & 1.97 & 3.06 & $22-35$ \\
21 & 2.00 & 2.78 & $24-40$ \\
22 & 1.58 & 5.76 & $22-45$ \\
\hline Average & 2.15 & 2.65 & - \\
\hline
\end{tabular}

The following parameters were used to produce the predictions. The relative dielectric permittivity of the buildings $\epsilon_{r}$ was chosen equal to 5 and the conductivity was zero. The specific attenuation constant $\alpha_{b}$ was taken to be $2.1 \mathrm{~dB} / \mathrm{m}$, which is the average of the empirical values found in Section IV. The base station antenna was omnidirectional and the pixel area was $5 \times 5 \mathrm{~m}^{2}$.

Fig. 10 shows area predictions of path loss, with and without considering transmission through buildings. The hatched circles in this figure indicate the locations and radii of trees, information that was extracted from aerial photographs of the area. For the predictions to be discussed at the end of this section, all trees were assumed to be $8 \mathrm{~m}$ high. In generating the prediction result shown in Fig. 10(a), the maximum number of wall transmissions was set to one, so that rays can penetrate buildings but cannot be transmitted through them. The results shown in Fig. 10(b), on the other hand, were obtained by setting the maximum transmission order to three, permitting rays to be transmitted through maximally one building and then penetrate a second one. The diffraction order was one and tree-scattering was initially not considered. The white observation areas (pixels) that can be seen in both subfigures correspond with areas that cannot be "reached" by rays of the order permitted. Obviously, a larger fraction of the total area can be reached if transmission through buildings is permitted. Significant differences between the prediction results of Fig. 10(a) and (b) are observed on Rodtmatt and Wiesen Streets, opposite to the base station. In these areas, differences up to approximately $50 \mathrm{~dB}$ occur. Hardly any difference can be seen in the streets perpendicular to the LOS street, which confirms the statement made earlier in this paper that transmission through buildings is not an important mechanism with regard to propagation around street corners.

A detailed comparison between measured data obtained from [2], [26], and predictions generated with and without considering 


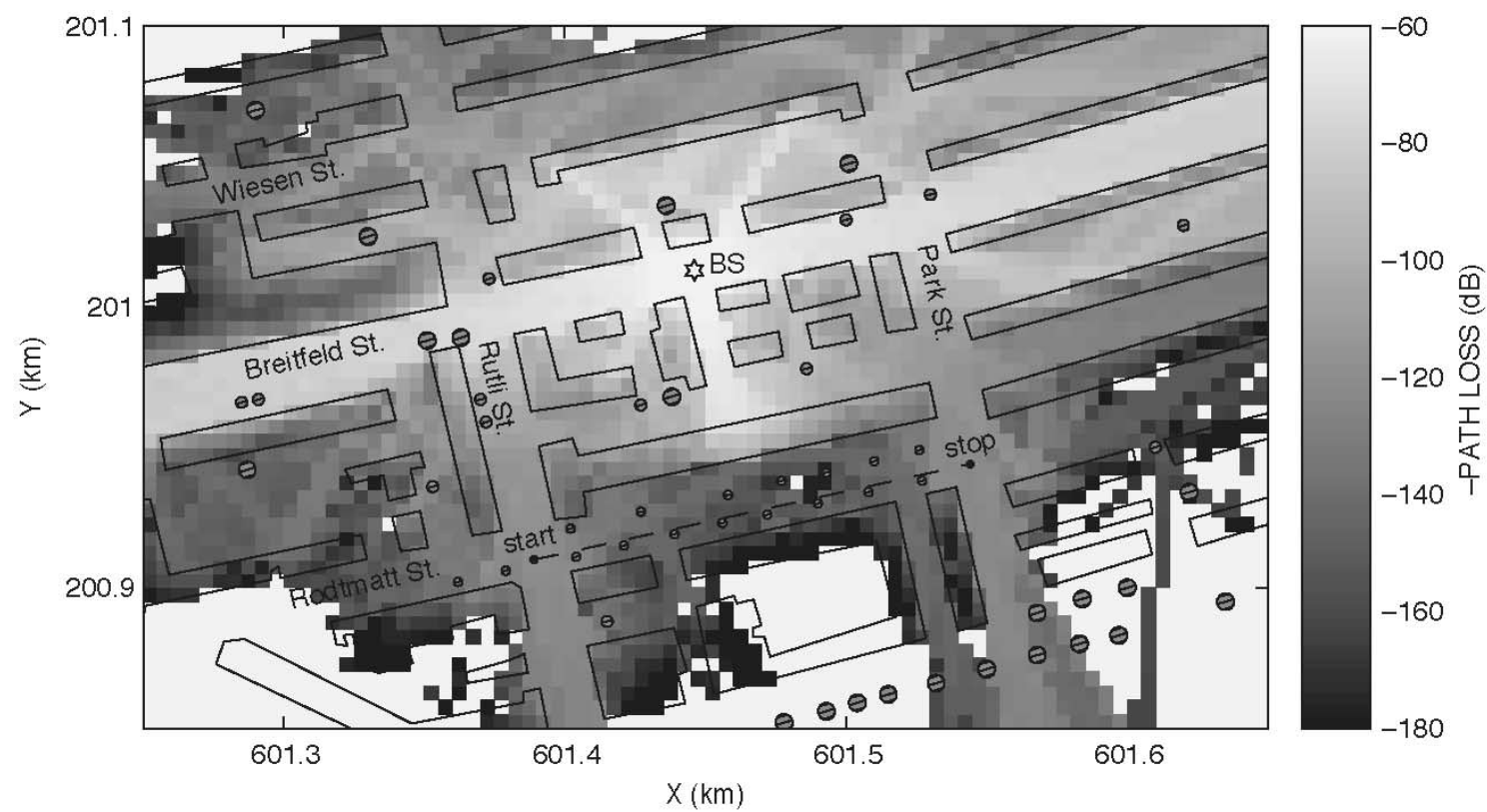

(a)

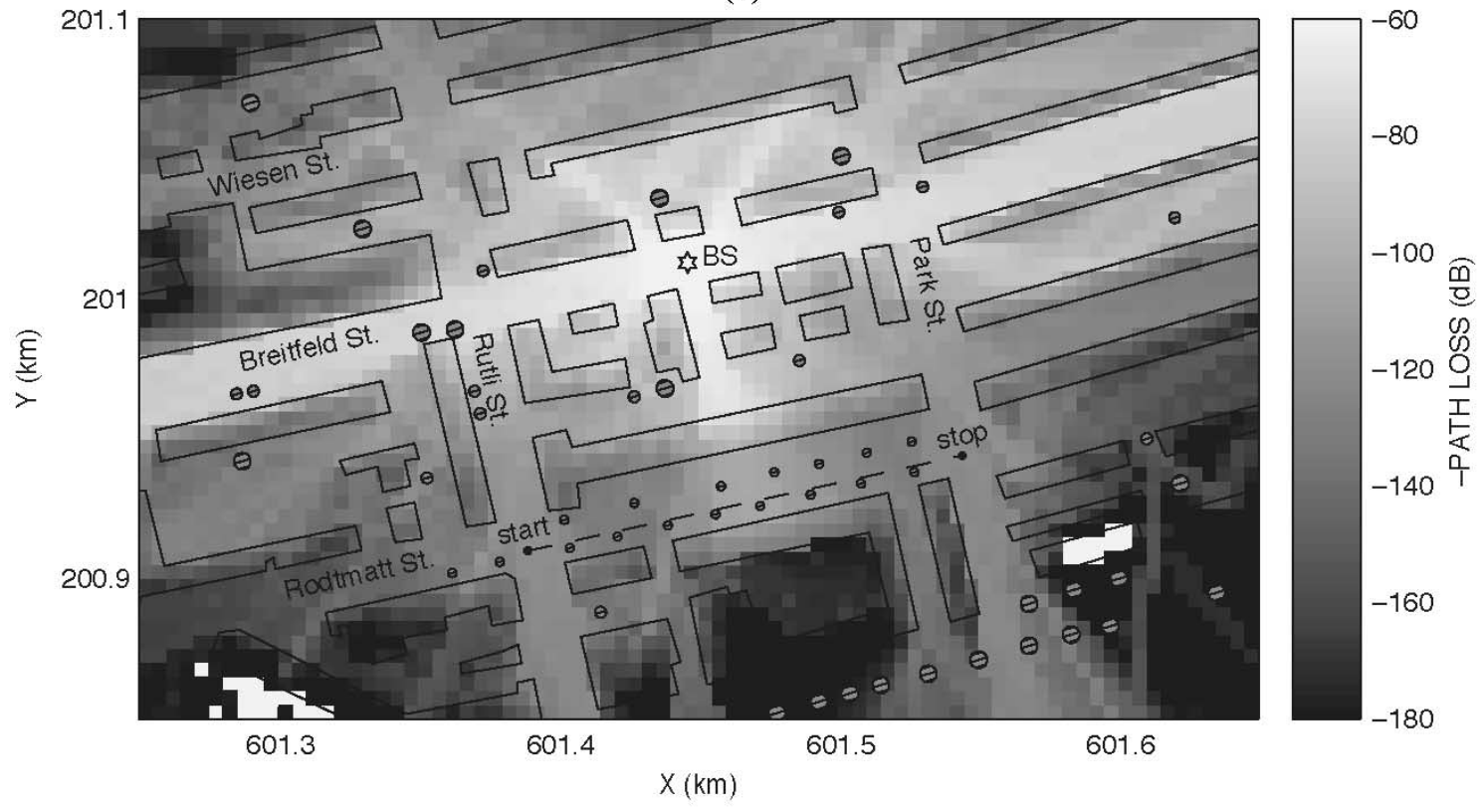

(b)

Fig. 10. Area predictions of local mean power for the urban microcell configuration in Bern, Switzerland, (a) without and (b) with consideration of transmission through buildings. Predictions were generated considering five reflections, one diffraction, and no scattering. Hatched circles represent trees and "BS" denotes the base station location.

building transmission was made for the trajectory indicated in Fig. 10. The number of observation points on this trajectory is 92. Table VII shows the mean and rms prediction errors obtained for various ray orders. This table also shows the number of virtual sources found in the ray-tracing procedure, which gives an indication of the computational complexity. The diffraction order was one and the scattering order was initially set to zero. For transmission order one and reflection orders lower than five, some points on the trajectory are not reached by at least one ray, so that the prediction error is meaningless. Increasing the reflection order is seen to gradually reduce the prediction error, until convergence is reached at some point. A very significant improvement is obtained, however, if rays are permitted to propagate through buildings. In that case, the rms error drops from 28 to $10 \mathrm{~dB}$. A further increase of the transmission order to five, allowing rays to be transmitted through two buildings, does not lead to further improvement. Table VII also shows the total number of sources found in the ray-tracing procedure. This number, and with it the computational load, is seen to rise sharply with the number of ray interactions considered. Yet, by considering building transmission, a much better prediction accuracy can be achieved at roughly the same computational load.

Fig. 11 shows the measured and predicted path loss along the trajectory for reflection order five, diffraction order one, and transmission orders one and three. Again, it can be clearly 
TABLE VII

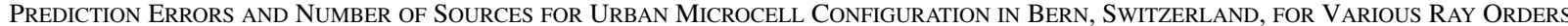

\begin{tabular}{|c|c|c|c|}
\hline Max. ray order & Number of sources & Mean error $(\mathrm{dB})$ & Rms error $(\mathrm{dB})$ \\
\hline 1 refl., 1 transm., 1 diffr., 0 scatt. & 759 & - & - \\
\hline 2 refl., 1 transm., 1 diffr., 0 scatt. & 2,844 & - & - \\
\hline 3 refl., 1 transm., 1 diffr., 0 scatt. & 7,313 & - & - \\
\hline 4 refl., 1 transm., 1 diffr., 0 scatt. & 15,488 & - & - \\
\hline 5 refl., 1 transm., 1 diffr., 0 scatt. & 28,771 & -29.9 & 33.8 \\
\hline 6 refl., 1 transm., 1 diffr., 0 scatt. & 49,098 & -28.5 & 32.0 \\
\hline 7 refl., 1 transm., 1 diffr., 0 scatt. & 78,466 & -26.5 & 29.8 \\
\hline 8 refl., 1 transm., 1 diffr., 0 scatt. & 119,621 & -25.3 & 28.2 \\
\hline 9 refl., 1 transm., 1 diffr., 0 scatt. & 174,984 & -25.4 & 28.3 \\
\hline 1 refl., 3 transm., 1 diffr., 0 scatt. & 2,215 & -16.1 & 20.0 \\
\hline 2 refl., 3 transm., 1 diffr., 0 scatt. & 11,525 & -10.7 & 14.2 \\
\hline 3 refl., 3 transm., 1 diffr., 0 scatt. & 36,760 & -9.0 & 12.0 \\
\hline 4 refl., 3 transm., 1 diffr., 0 scatt. & 91,406 & -7.9 & 10.9 \\
\hline 5 refl., 3 transm., 1 diffr., 0 scatt. & 193,645 & -7.4 & 10.5 \\
\hline 6 refl., 3 transm., 1 diffr., 0 scatt. & 367,947 & -7.2 & 10.3 \\
\hline 1 refl., 5 transm., 1 diffr., 0 scatt. & 5,093 & -14.4 & 17.8 \\
\hline 2 refl., 5 transm., 1 diffr., 0 scatt. & 32,575 & -10.1 & 13.5 \\
\hline 3 refl., 5 transm., 1 diffr., 0 scatt. & 120,311 & -8.7 & 11.6 \\
\hline 4 refl., 5 transm., 1 diffr., 0 scatt. & 338,360 & -7.6 & 10.6 \\
\hline 5 refl., 5 transm., 1 diffr., 0 scatt. & 795,070 & -7.1 & 10.2 \\
\hline 1 refl., 3 transm., 1 diffr., 1 scatt. & 40,209 & -5.9 & 9.3 \\
\hline 2 refl., 3 transm., 1 diffr., 1 scatt. & 238,197 & -3.4 & 6.8 \\
\hline 3 refl., 3 transm., 1 diffr., 1 scatt. & 869,898 & -2.5 & 5.8 \\
\hline 4 refl., 3 transm., 1 diffr., 1 scatt. & $2,462,996$ & -2.4 & 6.0 \\
\hline 5 refl., 3 transm., 1 diffr., 1 scatt. & $5,929,946$ & -2.1 & 5.9 \\
\hline
\end{tabular}

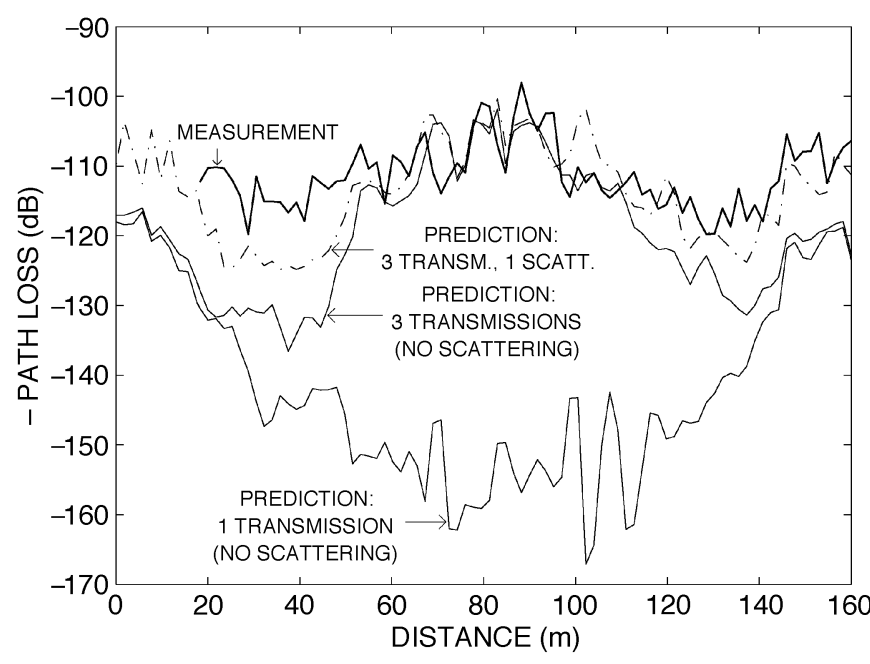

Fig. 11. Measured and predicted path loss along the trajectory in Bern, Switzerland. Predictions were generated considering five reflections and one diffraction.

seen that taking into account transmission through buildings results in a large improvement, especially in the middle part of the trajectory. A considerable difference between measurement and prediction remains near the intersection of Rutli and Park Street. As is illustrated by the dashed-dotted line in Fig. 11, this difference can partly be explained by the neglect of scattering from trees. Taking into account first-order scattering, using the tree-scattering model and leaf and branch parameters of [4], reduces the rms prediction error further, from 10 to $6 \mathrm{~dB}$, as shown in Table VII. Although it is not shown here, most of this improvement is due to considering the power scattered around street corners by trees located near intersections.

\section{CONCLUSION}

In this paper, a quasi-two-dimensional model has been presented for the propagation of radiowaves through buildings. This model can be integrated seamlessly in existing ray-based propagation tools based on reflection and diffraction, although it requires the ray-tracing engine to be modified such that it can handle rays going through one or more building walls. The model needs information about each building's exterior coordinates, its complex permittivity $\epsilon_{r}$, and a suitable choice of the attenuation factor $\alpha_{b}$, which is related to the internal building structure. Outdoor-to-indoor propagation (building penetration), which is receiving increased attention now that indoor coverage is becoming an important aspect of mobile network quality, is automatically taken into account as a "by-product." It is noted, however, that the present model can only be expected to provide good results for building penetration below the average rooftop level, due to its 2-D nature. A different model has to be used for the prediction of indoor field strength levels at higher floors. 
For a given value of $\epsilon_{r}$, the parameter $\alpha_{b}$ of a building can be obtained by fitting the expression for the building-transmission loss, defined as the path loss corresponding to a transmitted ray relative to free-space loss, to measured values of the building-transmission loss $L_{t}$ in the building's deep shadow. By means of a simple and accurate method that was also presented in this paper, measurements of $L_{t}$ were carried out for a set of 22 buildings at a frequency of $1.9 \mathrm{GHz}$. Empirical $\alpha_{b}$-values obtained from these measurements (assuming a permittivity of 5 and zero conductivity) range from 1.4 to $3.8 \mathrm{~dB} / \mathrm{m}$, but most are concentrated around the average value of $2.1 \mathrm{~dB} / \mathrm{m}$. If it is not feasible to determine $\alpha_{b}$ for each individual building, as will usually be the case in the practice of network planning, no large prediction errors are expected if all buildings are characterized by this average value.

It is noted that the $\alpha_{b}$ values obtained in this study are considerably higher than the specific attenuation factors reported in previous work based on the COST 231 building penetration model, which are typically in the range from 0.3 to $0.6 \mathrm{~dB} / \mathrm{m}$ at frequencies around $2 \mathrm{GHz}$ [7], [11], [12]. This discrepancy is most likely due to the fact that the COST model uses separate terms representing the losses inside the exterior and interior walls, whereas the coefficient $\alpha_{b}$ adopted herein accounts for all losses within the interface between the exterior wall and the free space surrounding the building, as discussed in Section II. Because the present model describes the building-transmission loss as being distributed uniformly along the transmitted ray path, it can be expected to be less accurate in the immediate vicinity of walls and other dominant obstructions within the building. However, as shown in Section IV, it provides a consistently good approximation of the transmitted field in the area behind the building. As stated earlier, one of the main advantages of the present building-transmission model over other models is that it does not require any knowledge about the building interior other than $\alpha_{b}$.

The building-transmission loss $L_{t}$ is usually in the range between 20 and $40 \mathrm{~dB}$, which is low considering that DSBs in the shadow area of a building can easily be more than $40 \mathrm{~dB}$ below the free-space level. Transmission through buildings is, therefore, often significant in heavily shadowed regions, which are typical for urban microcells. In fact, this mechanism was shown to be well measurable in all 22 experiments discussed in this paper. If disregarded in the planning stage of microcellular radio networks, unacceptable levels of cochannel interference may result.

An illustration of the potentially great improvement in propagation prediction accuracy achievable by considering "new" propagation mechanisms (building transmission, tree scattering) was given in the previous section. Improved prediction of radio channel characteristics is a key to more efficient radio network designs and to consequential savings in equipment, installation, and maintenance.

\section{ACKNOWLEDGMENT}

The authors would like to thank L. Wijdemans and J. Swijghuisen Reigersberg for their assistance in preparing and carrying out the experiments discussed in this paper.

\section{REFERENCES}

[1] V. Erceg, A. J. Rustako, and R. S. Roman, "Diffraction around corners and its effects on the microcell coverage area in urban and suburban environments at $900 \mathrm{MHz}, 2 \mathrm{GHz}$, and $6 \mathrm{GHz}$," IEEE Trans. Veh. Technol., vol. 43, pp. 762-766, Aug. 1994

[2] K. Rizk, J.-F. Wagen, and F. Gardiol, "Two-dimensional ray tracing modeling for propagation prediction in microcellular environments," IEEE Trans. Veh. Technol., vol. 46, pp. 508-518, May 1997.

[3] Y. L. C. de Jong, "Measurement and Modeling of Radiowave Propagation in Urban Microcells," Ph.D. dissertation, Eindhoven Univ. Technol., Eindhoven, The Netherlands, 2001.

[4] Y. L. C. de Jong and M. H. A. J. Herben, "A tree-scattering model for improved propagation prediction in urban microcells," IEEE Trans. Veh. Technol., vol. 53, pp. 503-513, Mar. 2004

[5] Y. L. C. de Jong, M. H. A. J. Herben, J.-F. Wagen, and A. Mawira, "Transmission of UHF radiowaves through buildings in urban microcell environments," Electron. Lett., vol. 35, no. 9, pp. 743-745, 1999.

[6] Y. L. C. de Jong, M. H. J. L. Koelen, and M. H. A. J. Herben, "Measurement of building transmission loss using wideband radio channel sounding," Electron. Lett., vol. 36, no. 12, pp. 1067-1069, 2000.

[7] COST 231, "Digital Mobile Radio Toward Future Generation Systems," Final report COST Telecom Secretariat, European Commission, Brussels, Belgium, 1999.

[8] J. Horikoshi, K. Tanaka, and T. Morinaga, "1.2 GHz band wave propagation measurements in concrete building for indoor radio communications," IEEE Trans. Veh. Technol., vol. VT-35, pp. 146-152, Nov. 1986.

[9] A. Davidson and C. Hill, "Measurement of building penetration into medium buildings at 900 and $1500 \mathrm{MHz}$," IEEE Trans. Veh. Technol., vol. 46, pp. 161-168, Feb. 1997.

[10] H. Börjeson and B. de Backer, "Angular dependency of line-of-sight building transmission loss at $1.8 \mathrm{GHz}$," in Proc. IEEE Ninth Int. Symp. PIMRC (PIMRC'98), Boston, MA, 1998, pp. 466-470.

[11] S. Stavrou, M. Fiacco, and S. R. Saunders, "Outdoor to indoor window penetration modeling at 2 and $5 \mathrm{GHz}$," in Proc. Millennium Conf. Antennas and Propagation (AP2000), Davos, Switzerland, 2000.

[12] Y. Miura, Y. Oda, and T. Taga, "Outdoor-to-indoor propagation modeling with the identification of path passing through wall openings," in Proc. 13th IEEE Int. Symp. Personal, Indoor and Mobile Radio Communications (PIMRC'02), Lisbon, Portugal, 2002, pp. 130-134.

[13] C. J. Haslett, "The transmission of microwaves through buildings," in Proc. Progress in Electromagnetic Research Symposium (PIERS'94), Noordwijk, The Netherlands, 1994, pp. 1-5.

[14] C. J. Haslett and D. A. Jacklin, "Site shielding reduction due to transmission through buildings in a city centre environment," in Proc. Ninth Int. Conf. Antennas and Propagation (ICAP'95), Eindhoven, The Netherlands, 1995, pp. 37-41.

[15] B. de Backer, F. Olyslager, and F. de Zutter, "An integral equation approach to the prediction of wave propagation in an indoor environment," in Proc. IEEE 3rd Symp. Commun. Veh. Technol. in the Benelux (SCVT'95), Eindhoven, The Netherlands, 1995, pp. 28-33.

[16] A. Lauer, "FDTD simulations of indoor propagation," in Proc. IEEE 44th Vehicular Technology Conference (VTC'94), Stockholm, Sweden, 1994, pp. 883-886.

[17] W. M. C. Dolmans, "Effect of Indoor Fading on the Performance of an Adaptive Antenna System," Ph.D. dissertation, Eindhoven Univ. Technol., Eindhoven, The Netherlands, 1997.

[18] W. Honcharenko, H. L. Bertoni, J. L. Dailing, J. Qian, and H. D. Yee, "Mechanisms governing UHF propagation on single floors in modern office buildings," IEEE Trans. Veh. Technol., vol. 41, pp. 496-504, Nov. 1992.

[19] S. Y. Seidel and T. S. Rappaport, "Site-specific propagation prediction for wireless in-building personal communication system design," IEEE Trans. Veh. Technol., vol. 43, pp. 879-891, Nov. 1994.

[20] C. A. Balanis, Advanced Engineering Electromagnetics. New York: Wiley, 1989.

[21] G. E. Athanasiadou and A. R. Nix, "Investigation into the sensitivity of the power predictions of a microcellular ray tracing propagation model," IEEE Trans. Veh. Technol., vol. 49, pp. 1140-1151, July 2000.

[22] R. Tiberio, G. Pelosi, and G. Manara, "A uniform GTD formulation for the diffraction by a wedge with impedance faces," IEEE Trans. Antennas Propagat., vol. AP-33, pp. 867-873, Aug. 1985.

[23] R. E. Burge, X.-C. Yuan, B. D. Caroll, N. E. Fisher, T. J. Hall, G. A Lester, N. D. Taket, and C. J. Oliver, "Microwave scattering from dielectric wedges with planar surfaces: a diffraction coefficient based on a physical optics version of GTD," IEEE Trans. Antennas Propagat., vol. 47, pp. 1515-1527, Oct. 1999. 
[24] Y. L. C. de Jong and M. H. A. J. Herben, "High-resolution angle-ofarrival measurement of the mobile radio channel," IEEE Trans. Antennas Propagat., vol. 47, pp. 1677-1687, Nov. 1999.

[25] W. C. Y. Lee, Mobile Communications Design Fundamentals. Indianapolis, IN: Sams, 1986.

[26] K. Rizk, "Propagation in Microcellular and Small Cell Urban Environment," Ph.D. dissertation, Ecole Polytechnique Fédérale de Lausanne, Lausanne, Switzerland, 1997.

[27] Y. L. C. de Jong and M. H. A. J. Herben, "Prediction of local mean power using 2-D ray-tracing-based propagation models," IEEE Trans. Veh. Technol., vol. 50, pp. 325-331, Jan. 2001.

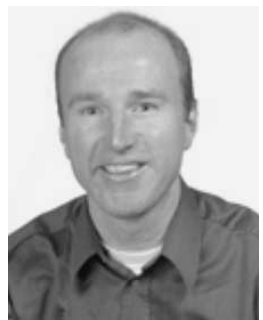

Yvo L. C. de Jong (S'96-M'01) received the M.Sc. (cum laude) and Ph.D. degrees in electrical engineering from the Eindhoven University of Technology, Eindhoven, The Netherlands, in 1996 and 2001, respectively.

He was with KPN Research (now TNO Telecom), Leidschendam, The Netherlands, from 1997 to 1998, in the framework of his Ph.D. dissertation work on deterministic propagation modeling for mobile communications. He visited Swisscom Corporate Information and Technology, Bern, Switzerland, in 1998. In 2001, he joined the Communications Research Centre Canada (CRC), Ottawa, ON, Canada, as a Research Scientist. His current research interest is in the area of multiple-input-multiple-output (MIMO) wireless systems.

Dr. de Jong's Ph.D. dissertation was nominated for the 2002 Telecommunication Award of the Dutch Royal Institute of Engineers (KIvI) and was awarded the second prize.

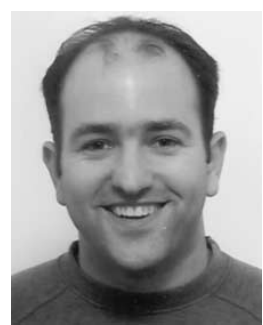

Maikel H. J. L. Koelen received the M.Sc. degree in electrical engineering from Eindhoven University of Technology (EUT), Eindhoven, the Netherlands, in 2000.

He is with Vodafone Netherlands, Maastricht, The Netherlands, as a Radio Planning Engineer.

Mr. Koelen received two awards for his M.Sc. thesis, which was on the measurement and modeling of radiowave transmission through buildings. In May 2001, he was awarded the Mignot Prize for best thesis work at EUT and in November 2001, he was awarded the Electrical Engineering Award of the Dutch Royal Institute of Engineers (KIvI).

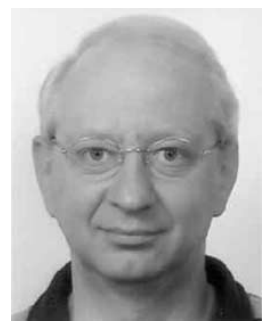

Matti H. A. J. Herben (S'80-M'83-SM'88) was born in Klundert, The Netherlands, in 1953. He received the M.Sc. degree (cum laude) in electrical engineering and the Ph.D. degree in technical sciences from Eindhoven University of Technology (EUT), Eindhoven, The Netherlands, in 1978 and 1984 , respectively.

Since 1978, he has been with the Radiocommunications Group of EUT, currently as an Associate Professor. His research interests and publications are in the areas of the design and numerical analysis of reflector and lens antenna systems, radio interference reduction, electromagnetic wave propagation on terrestrial and satellite links, remote sensing of the turbulent troposphere, and microwave radiometry.

Dr. Herben is a Member of the Royal Institute of Engineers (KIvI), the Netherlands Electronics and Radio Society (NERG), and the Dutch URSI Committee. He was an Associate Editor of Radio Science from 1993 to 1996. 